\title{
Associations of sirtuins with clinicopathological variables and prognosis in human ovarian cancer
}

\author{
QIKUAN HE ${ }^{1}$, KAI CHEN ${ }^{2}$, RUIFAN YE $^{3}$, NINGGAO DAI $^{3}$, PENGYI GUO $^{4}$ and LEIXI WANG ${ }^{5}$ \\ ${ }^{1}$ Department of General Surgery, Ningbo First Hospital, Ningbo, Zhejiang 315000; ${ }^{2}$ Department of Medicine, \\ Wenzhou Medical University Renji College, Wenzhou, Zhenjiang 325035; ${ }^{3}$ Department of Hepatobiliary Surgery, \\ The First Affiliated Hospital of Wenzhou Medical University, Wenzhou, Zhejiang 325015; \\ ${ }^{4}$ Department of Cardiothoracic Surgery, Ningbo Yinzhou No. 2 Hospital, Ningbo, Zhejiang 315192; \\ ${ }^{5}$ Department of Obstetrics and Gynecology, The Second Affiliated Hospital of Wenzhou Medical University, \\ Wenzhou, Zhejiang 325027, P.R. China
}

Received July 6, 2019; Accepted January 8, 2020

DOI: $10.3892 / \mathrm{ol} .2020 .11432$

\begin{abstract}
Ovarian cancer (OC) is the fifth most frequent cause of cancer-associated mortality worldwide, and is accompanied by asymptomatic progression. Sirtuins (SIRTs) are a family of nicotinamide adenine dinucleotide-dependent protein deacetylases, comprising seven members (SIRT1, SIRT2, SIRT3, SIRT4, SIRT5, SIRT6 and SIRT7). Accumulating evidence has demonstrated that SIRTs act as prognostic estimators in certain types of cancer such as lung cancer, prostate cancer, gastric cancer, breast cancer and colorectal cancer. However, it remains unknown whether individual SIRTs can serve as independent prognostic factors in OC. In the present study, the Kaplan-Meier plotter online database was utilized to examine the prognostic values of SIRT mRNA expression in patients with OC. The results demonstrated that the overexpression of SIRT3, SIRT5, SIRT6 and SIRT7 mRNAs was associated with a good prognosis in patients, whereas elevated mRNA levels of SIRT1 and SIRT4 indicated poor survival in patients with OC. In addition, among the favorable predictors, SIRT3, SIRT5, SIRT6 and SIRT7 overexpression were associated with overall survival (OS), according to clinical characteristics, such as histological classification, clinical stage, pathology grade, drug therapy and tumor protein p53 mutation status in patients with OC. Similarly, SIRT4 mRNA overexpression was
\end{abstract}

Correspondence to: Ms. Leixi Wang, Department of Obstetrics and Gynecology, The Second Affiliated Hospital of Wenzhou Medical University, 109 Xueyuan West Road, Wenzhou, Zhejiang 325027, P.R. China

E-mail: wangleiximouse@hotmail.com

Abbreviations: SIRT, sirtuin; OC, ovarian cancer; KM plotter, Kaplan-Meier plotter; OS, overall survival; PFS, progression-free survival; PPS, post-progression survival; HR, hazard ratio; CI, confidence interval; TP53, tumor protein p53; CRC, colorectal cancer

Key words: sirtuins, Kaplan-Meier plotter, ovarian cancer, prognosis, predictor associated with poor OS in pathological grade III cancer. High SIRT1 and SIRT4 expression were associated with unfavorable OS at all clinical stages. Furthermore, SIRT1 and SIRT4 were negatively associated with OS in drug-treated patients. In summary, the present study demonstrated that the SIRT family is associated with the prognosis of human OC, suggesting that individual SIRTs may also act as prognostic predictors in patients.

\section{Introduction}

Ovarian cancer (OC) is one of the most frequent causes of mortality associated with gynecologic malignancy, and the fifth leading cause of health issues among women and cancer-associated deaths worldwide during the past 2 decades $(1,2)$. A large number of patients $(>50 \%)$ are diagnosed at an advanced stage, mainly due to the asymptomatic development of OC (3). Currently, the therapeutic strategies for OC consist of radical surgical resection, chemotherapy based on taxanes and platinum, and targeted therapeutic management (4). Despite the aforementioned treatments, the overall survival (OS) rate remains at only $\sim 30 \%$ (5), partially due to drug resistance and a lack of specific biomarkers that can be used to detect the disease. Therefore, it is urgent to identify favorable prognostic factors of $\mathrm{OC}$ to improve the clinical outcomes of patients.

Sirtuins (SIRTs) are a family of deacetylases that comprises seven types in mammals (SIRT1-7), with different subcellular localization patterns and enzymatic activities (6). Since the discovery of SIRTs, the seven members, activated by nicotinamide adenine dinucleotide, have been closely associated with an extended life span by counteracting oxidative damage (7). Therefore, SIRTs could contribute greatly to aging (8). Among the seven identified SIRTs, SIRT1 is located in the nucleus; SIRT2 is located in the cytoplasm; SIRT3, SIRT4 and SIRT5 are localized in the mitochondria; and SIRT6 and SIRT7 are present in the nucleus. Notably, due to the unique ability of SIRTs to control the redox environment, accumulating evidence has demonstrated that SIRTs are involved in the pathology of various cancer types such as lung cancer, prostate cancer, gastric cancer and breast cancer (9-13). More specifically, 
previous studies have reported that SIRTs act as independent prognostic factors of several carcinomas, including colorectal cancer and non-small cell lung cancer $(14,15)$. To date, few individual SIRTs have been reported to be associated with OC. Shuang et al (16) found that SIRT1 could contribute to chemoresistance and the invasive capacity of OC cells, thereby boosting the proliferation of OC. Additionally, silencing of SIRT1 increases the protein expression of estrogen receptor $\beta$, which is regarded as an effective inhibitor of OC cells (17). On the other hand, SIRT3 exerts an antitumor effect on the induction of mitochondrial-dependent apoptosis via 5' AMP-activated protein kinase activation in OC cells (18). Regarding SIRT6, its dual roles as a tumor oncogene and suppressor in OC remain ambiguous $(19,20)$. Furthermore, the prognostic values of the SIRT family in OC remain to be elucidated. In the present study, using the Kaplan-Meier (KM) plotter, the prognostic significance of the SIRT transcription family was comprehensively investigated in patients with OC.

\section{Materials and methods}

Acquisition of data and statistical analysis. The prognostic values of individual SIRT mRNA levels from 1,657 patients with $\mathrm{OC}$ were investigated using the online $\mathrm{KM}$ plotter (http://kmplot.com/analysis) database. Until now, 54,675 genes are included in the database and thus can be examined to analyze the survival of patients with breast cancer (21), lung cancer (22), OC (23) and gastric cancer. In the present study, OS, progression-free survival (PFS) and post-progression survival (PPS) of patients with primary epithelial OC were assessed using the KM survival plot. Furthermore, clinical characteristics, including two main primary epithelial OC histologies, stage, grade, tumor protein p53 (TP53) mutation status and treatment choice were analyzed. Generally, seven SIRT subtypes (SIRT1, SIRT2, SIRT3, SIRT4, SIRT5, SIRT6 and SIRT7) were input into the database (http://kmplot. com/analysis/index.php?p=service \&cancer=ovar) to generate KM survival plots. Individuals were divided into two groups (high expression group and low expression group), according to the median expression of the SIRT gene. The hazard ratios (HRs) with 95\% CIs and log-rank $\mathrm{P}$ values were illustrated with the Cox proportional hazard model in the database. $\mathrm{P}<0.05$ was considered to indicate a statistically significant difference.

Tumor xenograft model. A2780 OC cells were purchased from American type culture collection and cultured to establish a nude mice tumor model. For culture, Dulbecco's modified Eagle's medium (DMEM) (Thermo Fisher Scientific, Inc.) containing streptomycin $(100 \mu \mathrm{g} / \mathrm{ml})$, penicillin $(100 \mathrm{U} / \mathrm{ml})$ and $10 \%$ FBS (Thermo Fisher Scientific, Inc.) were used. The medium was replaced every 2 days, and the cells were incubated in a moist atmosphere containing $5 \% \mathrm{CO}_{2}$ at $37^{\circ} \mathrm{C}$. Once adherent cells had grown to $\sim 90 \%$ confluence, the cells were digested with $0.25 \%$ trypsin- $0.02 \%$ EDTA for subculture and subsequent experimental treatment.

The athymic nude mice (BALB/C-nu/nu; age, 6 weeks; male; weight, 18-22 g) were purchased from Shanghai SLAC Laboratory Animal Co., Ltd. and bred in pathogen-free conditions under $22^{\circ} \mathrm{C}, 12 \mathrm{~h}$ light $/ 12 \mathrm{~h}$ dark, with free access to sterile water and food, in the Wenzhou Medical University Laboratory Animal Center (Wenzhou, China). A total of 15 randomized nude mice were used for the tumor xenograft model. The mice were anesthetized with, and $1 \times 10^{7}$ A2780 OC cells (in $100 \mu \mathrm{l}$ PBS) were injected subcutaneously into the armpit of each nude mouse. After 3 weeks, the mice were euthanized with $2 \%$ isoflurane excess carbon dioxide with the flow rate of $31 / \mathrm{min}$. The animal study was approved by the Wenzhou Medical University Ethics Committee (approval no. wydw2019-0214).

Immunohistochemical staining. The tumor tissues were harvested for immunohistochemistry. Tumor tissues were fixed in $4 \%$ paraformaldehyde at $25^{\circ} \mathrm{C}$ overnight, dehydrated with different concentrations of ethanol (75, 85, 95 and 100\%) and $100 \%$ dimethylbenzene separately, and embedded in paraffin. The specimens were subsequently cut into $4-\mu \mathrm{m}$ thick sections. The sections were rehydrated by placing them in a descending alcohol series (100, 90, 85 and 75\%) and $\mathrm{ddH}_{2} \mathrm{O}$ for $5 \mathrm{~min}$. Subsequently, the sections were washed with PBS for $5 \mathrm{~min}$. The washing step was repeated twice more. Following that, slides were placed in $0.01 \mathrm{M}$ sodium citrate buffer (Merck $\mathrm{KGaA}$ ) at $95^{\circ} \mathrm{C}$ for $5 \mathrm{~min}$ and then cooled to room temperature. The slides were blocked with $10 \%$ bovine serum albumin (BSA; Merck KGaA) for $1 \mathrm{~h}$ at $37^{\circ} \mathrm{C}$. Tissue sections were incubated with SIRT1 (1:200; cat. no. 13161-1-AP; Proteintech Group, Inc.), SIRT3 (1:200; cat. no. ab217319; Abcam) and SIRT6 (1:200; cat. no. 13572-1-AP; ProteinTech Group, Inc.) primary antibodies overnight at $4{ }^{\circ} \mathrm{C}$. Secondary antibody conjugated to horseradish peroxidase (1:200; cat. no. PV-6001; Origene Technologies, Inc.) was then added to the slides for $1 \mathrm{~h}$ at $37^{\circ} \mathrm{C}$ and 3,3'-diaminobenzidine were subsequently added to the slices for $2 \mathrm{~min}$. The sections were washed with PBS 3 times. The sections were dryed and stained with hematoxylin for 5 min followed by staining with differentiation solution for $1 \mathrm{~min}$. The sections were washed once with running water for $10 \mathrm{~min}$ and covered with a coverslip of neutral resin. An inverted light microscope was used to observe the expression of SIRT1, SIRT3 and SIRT6 in the tumor tissues at a magnification of $\mathrm{x} 200$.

\section{Results}

Multivariate analysis and survival outcomes of patients with OC based on the expression of SIRTs. KM survival data on all seven SIRT members examined in the present study can be acquired from www.kmplot.com. Firstly, the prognostic value of SIRT1 (Affymetrix ID, 218878_s_at) was evaluated. OS, PFS and PPS curves were generated for all patients with OC (Fig. 1A). High SIRT1 expression was significantly associated with worse OS ( $\mathrm{P}=0.0029 ; \mathrm{HR}, 1.22 ; 95 \% \mathrm{CI}, 1.07-1.39)$ and PFS ( $\mathrm{P}=0.016$; HR, 1.17; 95\% CI, 1.03-1.33). However, there was no association identified between SIRT1 and PPS $(\mathrm{P}=0.2$; HR, 1.12; 95\% CI, 0.94-1.34). In the present study, the two common histological subtypes of ovarian cancer (endometrioid and serous cancer) were used for subsequent analyses. Furthermore, the OS curves of patients with different OC subtypes were plotted (Fig. 1B). The results demonstrated that the OS of patients with endometrioid cancer $(\mathrm{P}=0.053$; $\mathrm{HR}, 4.94$; $95 \% \mathrm{CI}, 0.82-29.69)$ or serous cancer $(\mathrm{P}=0.074$; 


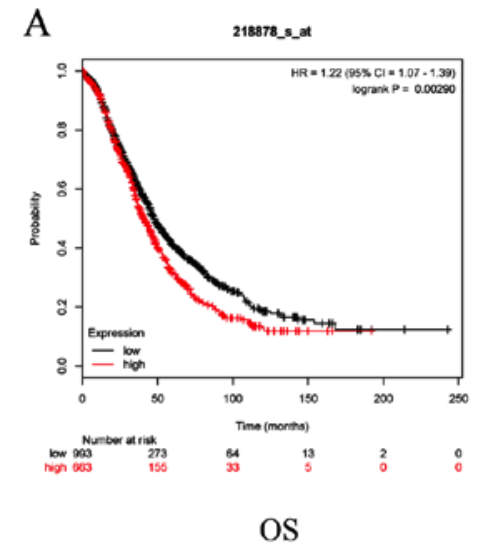

SIRT1 All subtypes of ovarian cancer
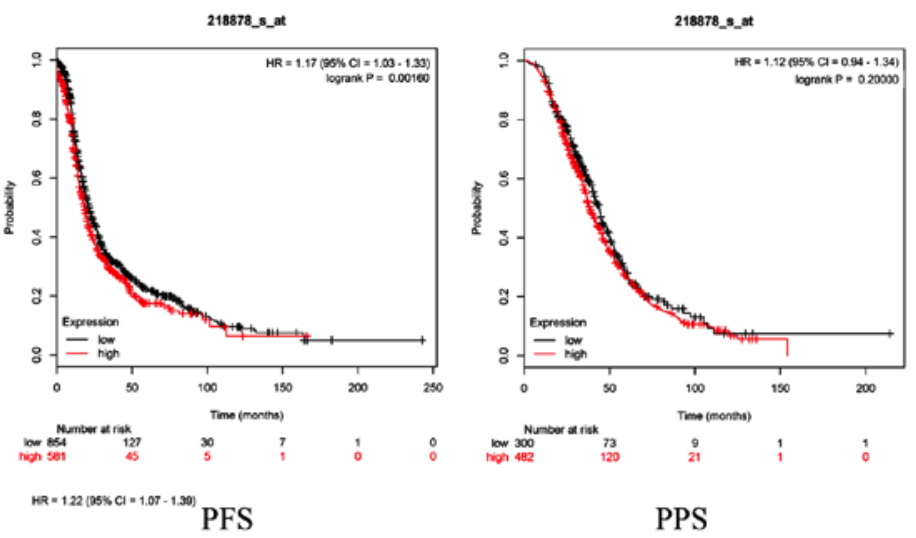

B

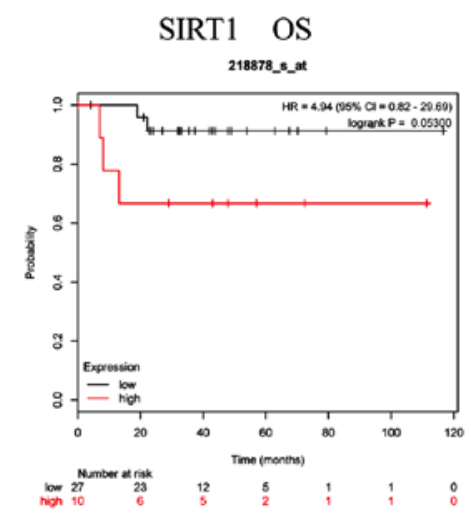

Endometrioid cancer

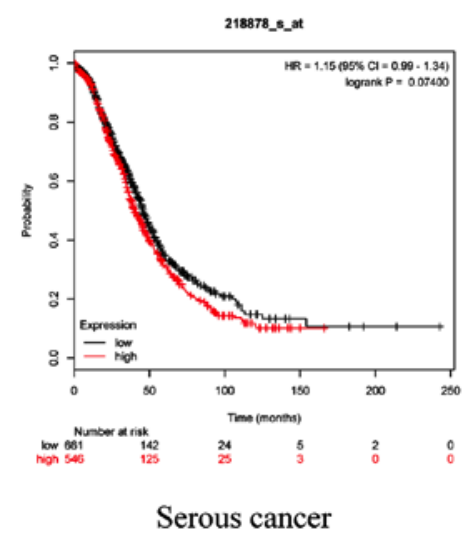

Figure 1. Prognostic significance of SIRT1 mRNA expression in OC patients. Prognostic significance of SIRT1 mRNA expression (A) in all patients with OC and (B) in patients with different subtypes of OC. All patients with $\mathrm{OC}, \mathrm{n}=1,656$; patients with endometrioid cancer, $\mathrm{n}=37$; patients with serous cancer, $\mathrm{n}=1,207$. OC, ovarian cancer; SIRT, sirtuin; OS, overall survival; PFS, progression-free survival; PPS, post-progression survival; HR, hazard ratio.

HR, 1.15; 95\% CI, 0.99-1.34) was not associated with SIRT1 mRNA expression.

Furthermore, the prognostic significance of SIRT2 mRNA expression (Affymetrix ID, 220605_s_at) was analyzed. Elevated SIRT2 levels were significantly associated with PFS $(\mathrm{P}=0.025$; HR, 0.85; 95\% CI, 0.74-0.98) and PPS ( $\mathrm{P}=0.011$; $\mathrm{HR}, 1.27$; 95\% CI, 1.06-1.53) in patients with OC (Fig. 2A). By contrast, mRNA expression levels of SIRT2 in patients with OC did not exhibit any association with $\mathrm{OS}(\mathrm{P}=0.4$; HR, 0.95; 95\% CI, 0.83-1.08). Histological subtype outcomes indicated that SIRT2 expression had no effect on the OS of patients with endometrioid cancer $(\mathrm{P}=0.19 ; \mathrm{HR}, 3.84 ; 95 \% \mathrm{CI}, 0.43-34.41)$ or serous cancer $(\mathrm{P}=0.17$; HR, 1.13; 95\% CI, 0.95-1.33; Fig. 2B).

Additionally, the prognostic role of SIRT3 mRNA expression (Affymetrix ID, 221913_at) was examined (Fig. 3A and B). High expression of SIRT3 was associated with favorable OS $(\mathrm{P}=0.00093 ; \mathrm{HR}, 0.8 ; 95 \% \mathrm{CI}, 0.7-0.91)$ and PPS ( $\mathrm{P}=0.045$; HR, 0.84; 95\% CI, 0.71-1.00) in patients with OC. However, there was no significant association between PFS and SIRT3 mRNA levels in patients with OC $(\mathrm{P}=0.083$; $\mathrm{HR}, 0.89$; 95\% CI, 0.77-1.02). With regard to serous cancer, high expression of SIRT3 exhibited an evident effect on OS among patients with $\mathrm{OC}(\mathrm{P}=0.00962 ; \mathrm{HR}, 0.82 ; 95 \% \mathrm{CI}$, 0.7-0.95). Furthermore, there was no significant association between the SIRT3 mRNA levels and the OS of patients with endometrioid cancer ( $\mathrm{P}=0.38$; HR, 0.46; 95\% CI, 0.08-2.75).
Subsequently, the prognostic implications of SIRT4 mRNA expression (Affymetrix ID, 220047_at) were explored. High mRNA expression levels of SIRT4 were significantly associated with unfavorable OS $(\mathrm{P}=0.0012 ; \mathrm{HR}, 1.24 ; 95 \% \mathrm{CI}$, 1.09-1.41), PFS (P=0.00017; HR, 1.27; 95\% CI, 1.12-1.44) and PPS ( $\mathrm{P}=0.013$; HR, 1.24; 95\% CI, 1.05-1.47) in patients with OC (Fig. 4A). Additionally, increased SIRT4 mRNA expression also indicated poor OS in patients with both endometrioid cancer $(\mathrm{P}=0.016$; HR, 9.36; $\mathrm{CI}, 1.04-84.6)$ and serous cancer $(\mathrm{P}=0.011$; HR, 1.22; 95\% CI, 1.05-1.42; Fig. 4B).

The prognostic importance of SIRT5 mRNA expression (Affymetrix ID, 229112_at) was subsequently examined. Interestingly, enhanced SIRT5 mRNA levels were notably associated with improved OS ( $\mathrm{P}=0.048 ; \mathrm{HR}, 0.81 ; 95 \% \mathrm{CI}$, 0.66-1.00) and PPS (P=0.0011; HR, 0.66; 95\% CI, 0.52-0.85), but with poor PFS $(\mathrm{P}=0.0018$; HR, 1.36; $95 \% \mathrm{CI}, 1.12-1.65$; Fig. 5A). Additionally, Fig. 5B reveals the association between SIRT5 and the OC subtypes. It was clear that the upregulation of SIRT5 mRNA expression was notably associated with favorable $\mathrm{OS}$ in serous cancer $(\mathrm{P}=0.036$; $\mathrm{HR}, 0.78 ; 95 \% \mathrm{CI}$, 0.62-0.98). However, SIRT5 mRNA expression was not associated with $\mathrm{OS}$ in patients with endometrioid cancer $(\mathrm{P}=0.32$; HR, 3.01; 95\% CI, 0.31-29).

Subsequently, the prognostic significance of SIRT6 mRNA expression levels (Affymetrix ID, 219613_s_at) was investigated. High SIRT6 expression was significantly associated 


\section{SIRT2 All subtypes of ovarian cancer}

A

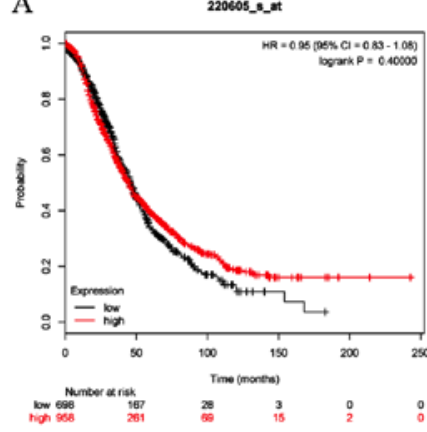

OS

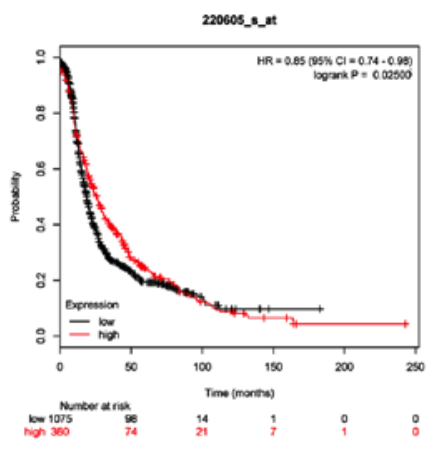

PFS

B
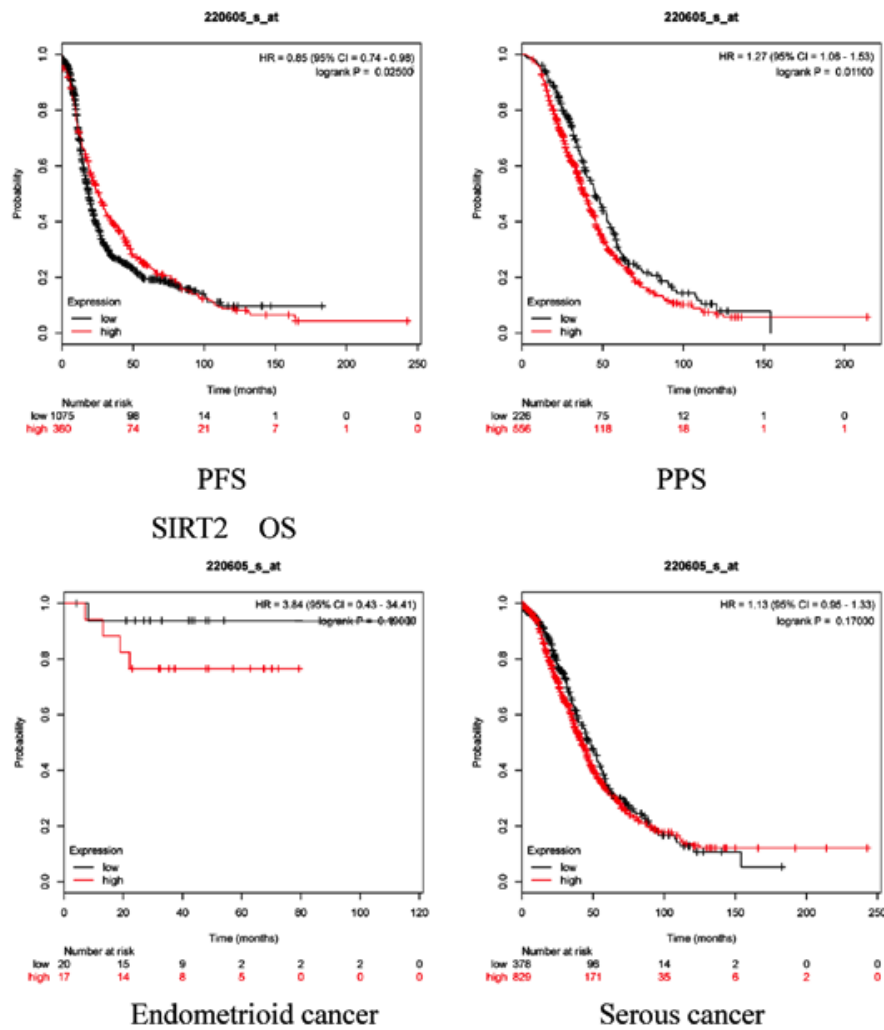

PPS

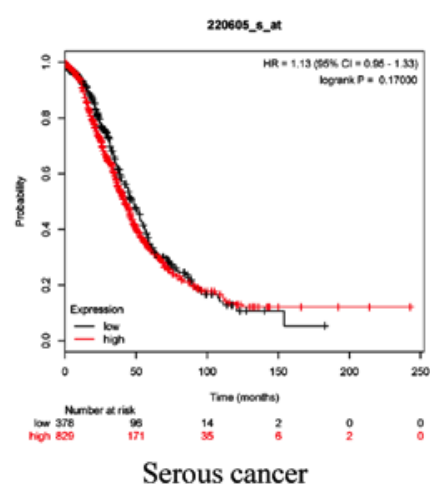

Figure 2. Prognostic significance of SIRT2 mRNA expression in OC patients. Prognostic significance of SIRT2 mRNA expression (A) in all patients with OC and (B) in patients with different subtypes of OC. All patients with OC, $n=1,656$; patients with endometrioid cancer, $n=37$; patients with serous cancer, $n=1,207$. OC, ovarian cancer; SIRT, sirtuin; OS, overall survival; PFS, progression-free survival; PPS, post-progression survival; HR, hazard ratio.

\section{SIRT3 All subtypes of ovarian cancer}
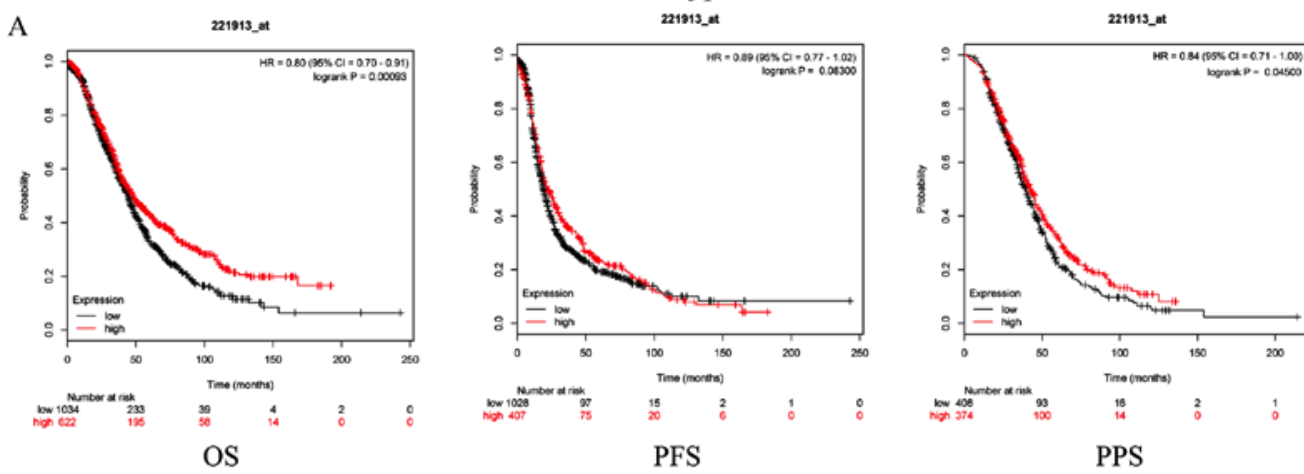

SIRT3 OS

B
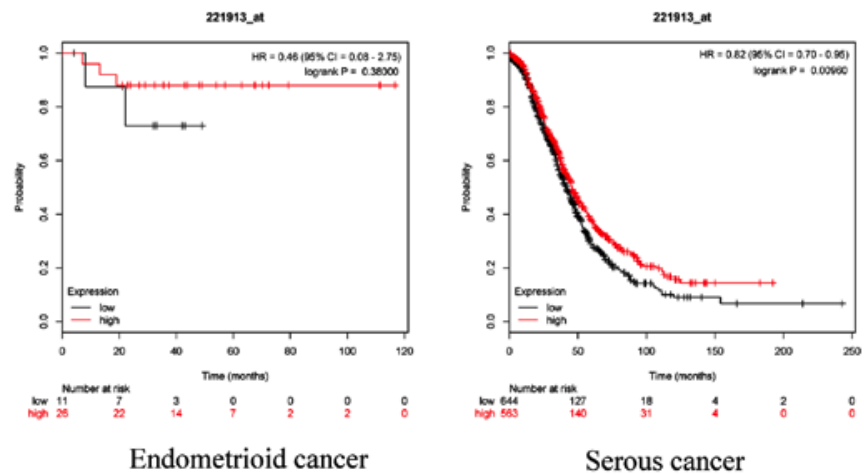

Figure 3. Prognostic significance of SIRT3 mRNA expression in OC patients. Prognostic significance of SIRT3 mRNA expression (A) in all patients with OC and (B) in patients with different subtypes of OC. All patients with OC, $n=1,656$; patients with endometrioid cancer, $\mathrm{n}=37$; patients with serous cancer, $\mathrm{n}=1,207$. OC, ovarian cancer; SIRT, sirtuin; OS, overall survival; PFS, progression-free survival; PPS, post-progression survival; HR, hazard ratio. 
SIRT4 All subtypes of ovarian cancer

A

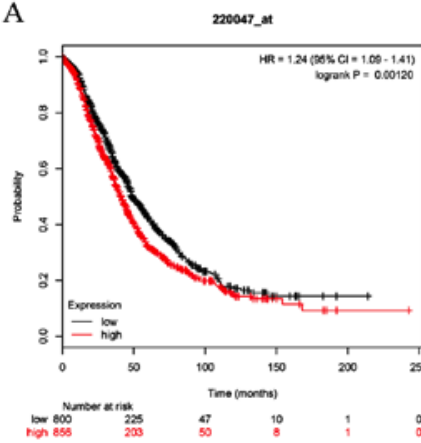

OS

B

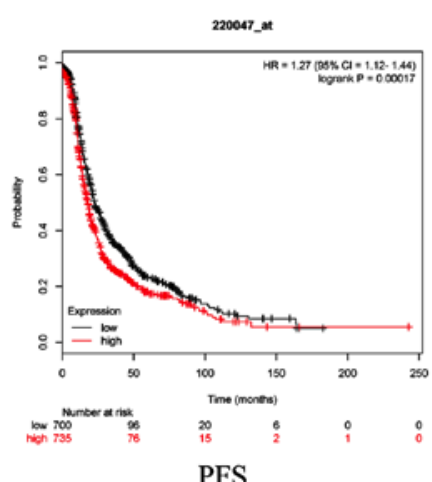

PFS

SIRT4 OS

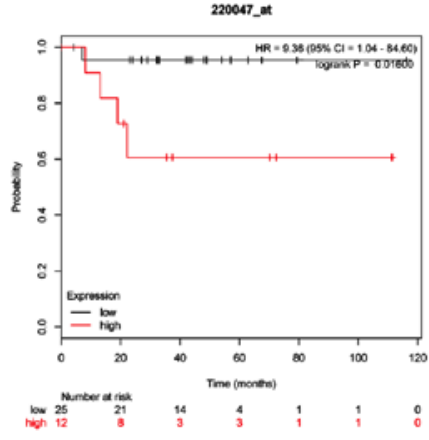

Endometrioid cancer
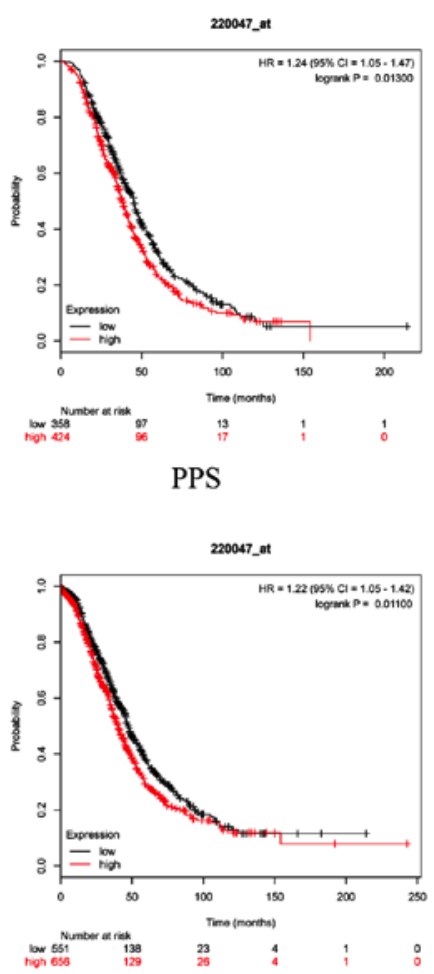

Serous cancer

Figure 4. Prognostic significance of SIRT4 mRNA expression in OC patients. Prognostic significance of SIRT4 mRNA expression (A) in all patients with OC and (B) in patients with different subtypes of OC. All patients with OC, $n=1,656$; patients with endometrioid cancer, $n=37$; patients with serous cancer, $n=1,207$. OC, ovarian cancer; SIRT, sirtuin; OS, overall survival; PFS, progression-free survival; PPS, post-progression survival; HR, hazard ratio.

\section{SIRT5 All subtypes of ovarian cancer}

A

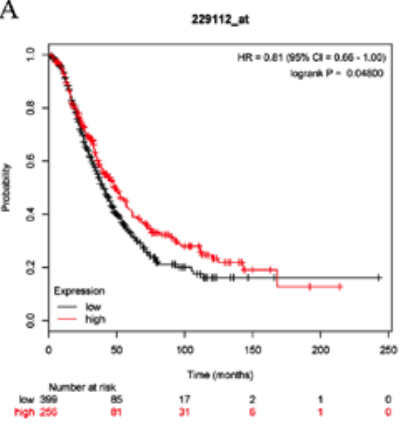

OS

B

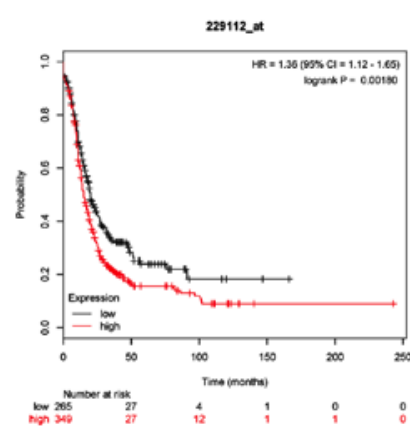

PFS

SIRT5 OS

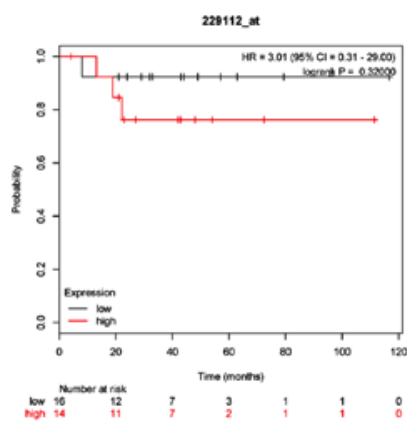

Endometrioid cancer

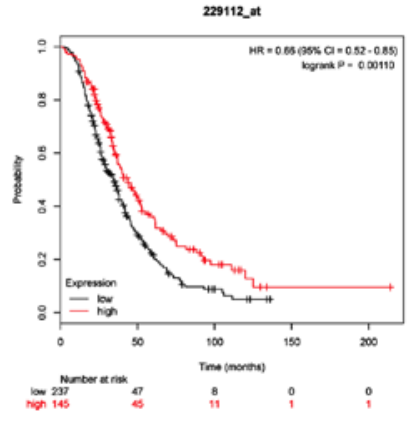

PPS

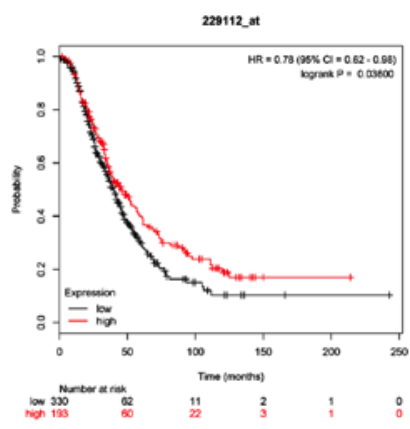

Serous cancer

Figure 5. Prognostic significance of SIRT5 mRNA expression in OC patients. Prognostic significance of SIRT5 mRNA expression (A) in all patients with OC and (B) in patients with different subtypes of OC. All patients with OC, $n=1,656$; patients with endometrioid cancer, $\mathrm{n}=37$; patients with serous cancer, $\mathrm{n}=1,207$. OC, ovarian cancer; SIRT, sirtuin; OS, overall survival; PFS, progression-free survival; PPS, post-progression survival; HR, hazard ratio. 
SIRT6 All subtypes of ovarian cancer

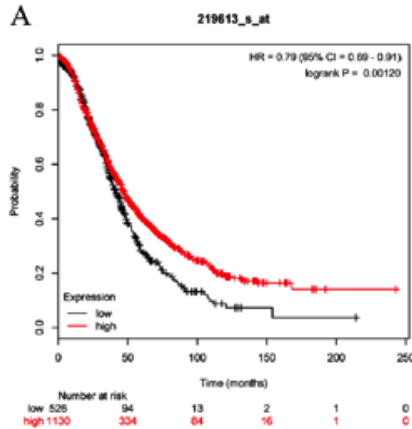

OS

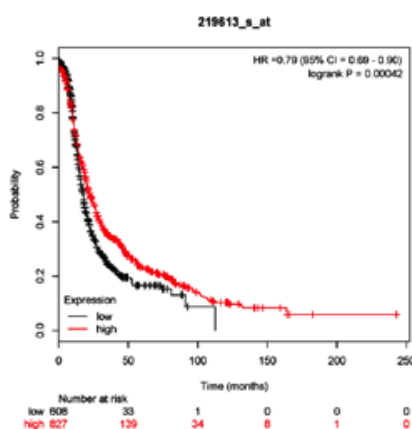

PFS

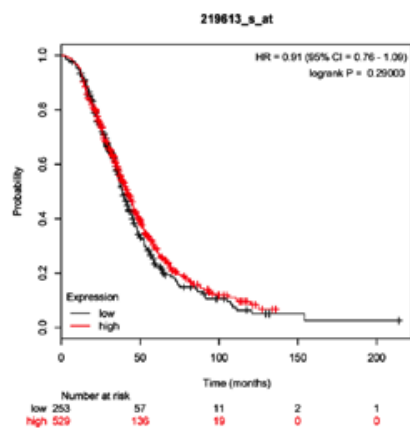

PPS

B

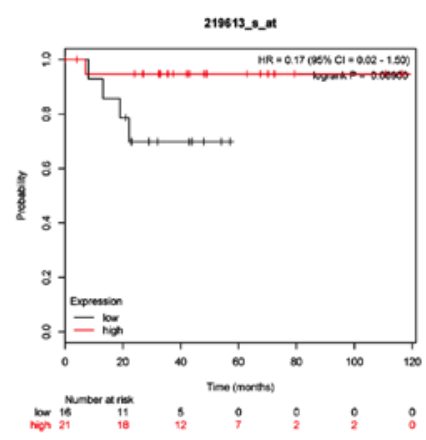

Endometrioid cancer

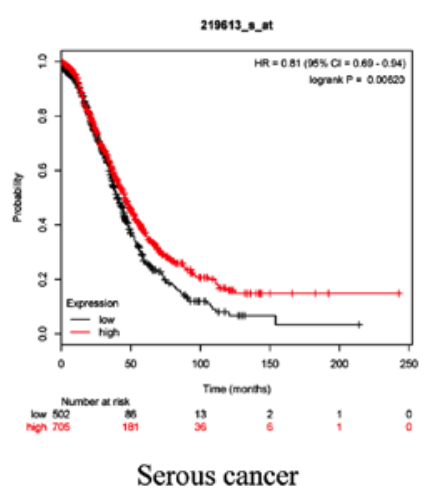

Serous cancer

Figure 6. Prognostic significance of SIRT6 mRNA expression in OC patients. Prognostic significance of SIRT6 mRNA expression (A) in all patients with OC and (B) in patients with different subtypes of OC. All patients with OC, $n=1,656$; patients with endometrioid cancer, $n=37$; patients with serous cancer, $n=1,207$. OC, ovarian cancer; SIRT, sirtuin; OS, overall survival; PFS, progression-free survival; PPS, post-progression survival; HR, hazard ratio.

SIRT7 All subtypes of ovarian cancer

A

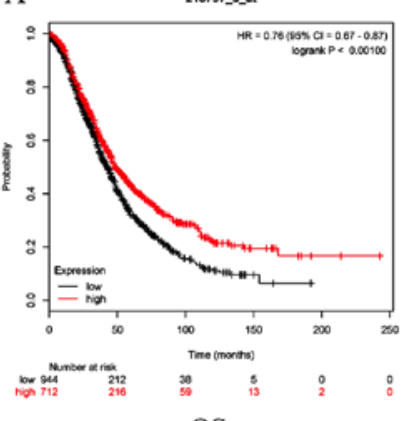

OS

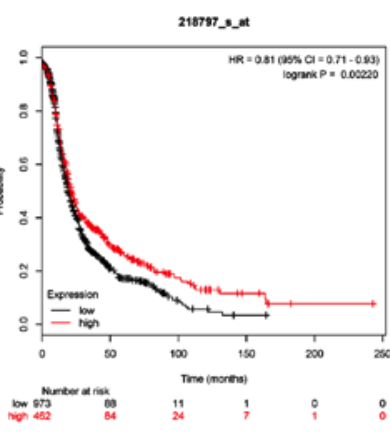

PFS

SIRT7 OS

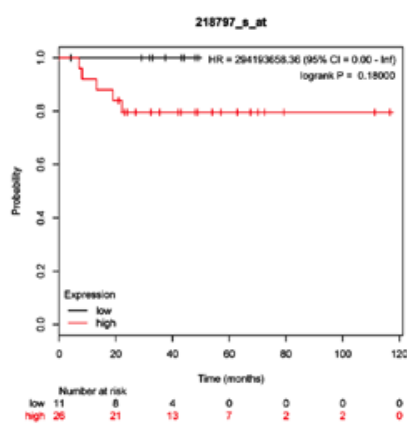

Endometrioid cancer

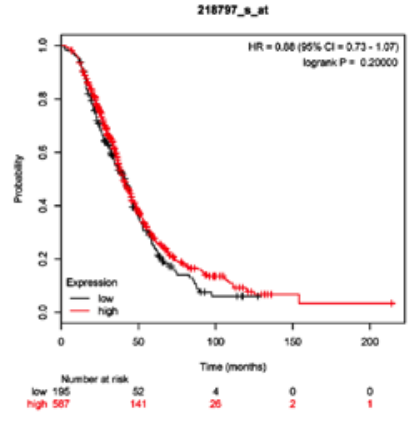

PPS

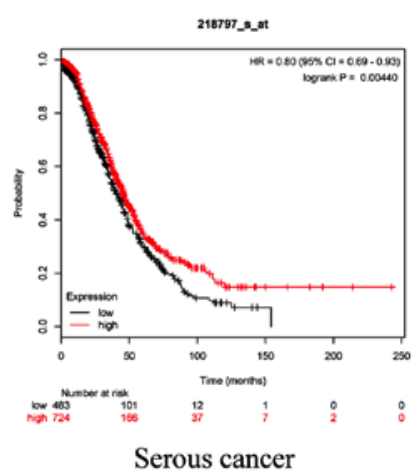

Figure 7. Prognostic significance of SIRT7 mRNA expression in OC patients. Prognostic significance of SIRT7 mRNA expression in (A) all patients with OC and (B) in patients with different subtypes of OC. All patients with $\mathrm{OC}, \mathrm{n}=1,656$; patients with endometrioid cancer, $\mathrm{n}=37$; patients with serous cancer, $\mathrm{n}=1,207$. OC, ovarian cancer; SIRT, sirtuin; OS, overall survival; PFS, progression-free survival; PPS, post-progression survival; HR, hazard ratio. 
Table I. Associations between elevated SIRT mRNA expression and overall survival of all patients with ovarian cancer, according to different pathological grades.

\begin{tabular}{|c|c|c|c|c|}
\hline SIRT & $\begin{array}{l}\text { Pathological } \\
\text { grade }\end{array}$ & Cases, $\mathrm{n}$ & $\begin{array}{c}\mathrm{HR} \\
(95 \% \mathrm{CI})\end{array}$ & P-value \\
\hline \multirow[t]{3}{*}{ SIRT1 } & I & 56 & $0.68(0.25-1.68)$ & 0.4498 \\
\hline & II & 324 & $1.29(0.95-1.77)$ & 0.1025 \\
\hline & III & 1,015 & $1.18(0.99-1.41)$ & 0.0719 \\
\hline \multirow[t]{3}{*}{ SIRT2 } & I & 56 & $3.04(0.98-9.38)$ & 0.0425 \\
\hline & II & 324 & $0.82(0.58-1.15)$ & 0.2536 \\
\hline & III & 1,015 & $1.10(0.92-1.33)$ & 0.3024 \\
\hline \multirow[t]{3}{*}{ SIRT3 } & I & 56 & $1.75(0.67-4.55)$ & 0.2446 \\
\hline & II & 324 & $0.58(0.43-0.79)$ & 0.0005 \\
\hline & III & 1,015 & $0.84(0.70-1.00)$ & 0.0522 \\
\hline \multirow[t]{3}{*}{ SIRT4 } & I & 56 & $0.71(0.28-1.81)$ & 0.4768 \\
\hline & II & 324 & $1.24(0.91-1.69)$ & 0.1805 \\
\hline & III & 1,015 & $1.32(1.10-1.58)$ & 0.0026 \\
\hline \multirow[t]{3}{*}{ SIRT5 } & I & 41 & $2.06(0.71-6.96)$ & 0.1744 \\
\hline & II & 162 & $0.71(0.44-1.13)$ & 0.1488 \\
\hline & III & 392 & $0.81(0.61-1.08)$ & 0.1560 \\
\hline \multirow[t]{3}{*}{ SIRT6 } & I & 56 & $0.43(0.16-1.13)$ & 0.0792 \\
\hline & II & 324 & $0.61(0.45-0.83)$ & 0.0013 \\
\hline & III & 1,015 & $0.82(0.69-0.97)$ & 0.0183 \\
\hline \multirow[t]{3}{*}{ SIRT7 } & I & 56 & $0.63(0.24-1.64)$ & 0.3374 \\
\hline & II & 324 & $0.78(0.57-1.05)$ & 0.1052 \\
\hline & III & 1,015 & $0.73(0.61-0.88)$ & 0.0008 \\
\hline
\end{tabular}

Pathological grades were classified according to the pathological classification (52). SIRT, sirtuin; HR, hazard ratio.

with improved OS ( $\mathrm{P}=0.0012$; HR, 0.79; 95\% CI, 0.69-0.91) and PFS (P=0.00042; HR, 0.79; 95\% CI, 0.69-0.90) in patients with OC. Despite these results, SIRT6 exhibited no effect on PPS (P=0.29; HR, 0.91; 95\% CI, 0.76-1.09) in patients with OC (Fig. 6A). With respect to the histological subtype of OC, elevated SIRT6 mRNA expression was associated with good OS in patients with serous cancer $(\mathrm{P}=0.0062$; HR, 0.81; 95\% CI, 0.69-0.94), but not in patients with endometrioid cancer ( $\mathrm{P}=0.069$; HR, 0.17; 95\% CI, 0.02-1.50; Fig. 6B).

Finally, the prognostic role of SIRT7 (Affymetrix ID, 218797_s_at) was studied. High SIRT7 mRNA expression was significantly associated with good $\mathrm{OS}\left(\mathrm{P}=5.3 \times 10^{-5} ; \mathrm{HR}, 0.76\right.$; 95\% CI, 0.67-0.87) and PFS (P=0.0022; HR, 0.81; 95\% CI, 0.71-0.93) in all patients with OC. However, there was no association between SIRT7 expression and PPS $(\mathrm{P}=0.2$; HR, 0.88; 95\% CI, 0.73-1.07) in patients diagnosed with OC (Fig. 7A). Regarding the subtypes, increased SIRT7 mRNA levels were significantly associated with improved OS in patients with serous cancer $(\mathrm{P}=0.0044$; HR, 0.8; 95\% CI, 0.69-0.93), but not in patients with endometrioid cancer $[\mathrm{P}=0.18$; HR, 294,193,658.36 (0-inf); Fig. 7B].

Associations between high mRNA expression levels of SIRT members and other clinicopathological characteristics. Additionally, the associations of each SIRT family
Table II. Associations between elevated SIRT mRNA expression and overall survival of all patients with ovarian cancer, according to different clinical stages.

\begin{tabular}{lcrcc}
\hline SIRT & $\begin{array}{c}\text { Clinical } \\
\text { stages }\end{array}$ & Cases, n & $\begin{array}{c}\text { HR } \\
(95 \% \mathrm{CI})\end{array}$ & P-value \\
\hline SIRT1 & I+II & 135 & $1.96(0.90-4.28)$ & 0.0862 \\
& III+IV & 1,220 & $1.18(1.02-1.37)$ & 0.0298 \\
SIRT2 & I+II & 135 & $0.50(0.23-1.09)$ & 0.0763 \\
& III+IV & 1,220 & $1.11(0.94-1.31)$ & 0.2335 \\
SIRT3 & I+II & 135 & $0.51(0.19-1.35)$ & 0.1682 \\
& III+IV & 1,220 & $0.75(0.64-0.89)$ & 0.0007 \\
SIRT4 & I+II & 135 & $0.52(0.20-1.40)$ & 0.1883 \\
& III+IV & 1,220 & $1.26(1.07-1.49)$ & 0.0052 \\
SIRT5 & I+II & 83 & $1.93(0.70-5.36)$ & 0.1976 \\
& III+IV & 487 & $0.68(0.54-0.87)$ & 0.0015 \\
SIRT6 & I+II & 135 & $0.23(0.07-0.77)$ & 0.009 \\
& III+IV & 1,220 & $0.77(0.67-0.90)$ & 0.0008 \\
SIRT7 & I+II & 135 & $0.37(0.17-0.81)$ & 0.0097 \\
& III+IV & 1,220 & $0.83(0.71-0.96)$ & 0.0130 \\
\hline
\end{tabular}

The number of patients expressing SIRT5 is different compared with all the other SIRT genes. The expression level of SIRT5 is affected by factors such as study design, patient selection and statistical analyses. Clinical stage was classified according to the FIGO (International Federation of Gynecology and Obstetrics) classification (53). SIRT, sirtuin; HR, hazard ratio.

Table III. Associations between elevated SIRT mRNA expression and overall survival of all patients with ovarian cancer, according to the TP53 mutation condition.

\begin{tabular}{llrll}
\hline SIRT & TP53 mutation & Cases, $\mathrm{n}$ & HR $(95 \% \mathrm{CI})$ & P-value \\
\hline SIRT1 & Mutant & 506 & $1.21(0.95-1.53)$ & 0.1256 \\
& Wild & 94 & $1.53(0.85-2.76)$ & 0.1545 \\
SIRT2 & Mutant & 506 & $1.55(1.22-1.97)$ & 0.0003 \\
& Wild & 94 & $0.64(0.37-1.12)$ & 0.1153 \\
SIRT3 & Mutant & 506 & $0.51(0.19-1.35)$ & 0.0072 \\
& Wild & 94 & $0.54(0.29-0.99)$ & 0.0432 \\
SIRT4 & Mutant & 506 & $1.19(0.94-1.49)$ & 0.1407 \\
& Wild & 94 & $1.69(0.95-3.02)$ & 0.0720 \\
SIRT5 & Mutant & 124 & $0.50(0.32-0.77)$ & 0.0015 \\
& Wild & 19 & $0.51(0.16-1.64)$ & 0.2497 \\
SIRT6 & Mutant & 506 & $1.17(0.92-1.49)$ & 0.2102 \\
& Wild & 94 & $0.67(0.38-1.18)$ & 0.1677 \\
SIRT7 & Mutant & 506 & $1.19(0.94-1.50)$ & 0.1515 \\
& Wild & 94 & $1.30(0.72-2.34)$ & 0.3808 \\
& & & &
\end{tabular}

The number of patients expressing SIRT5 is different compared with all the other SIRT genes. The expression level of SIRT5 is affected by factors such as study design, patient selection and statistical analyses. SIRT, sirtuin; HR, hazard ratio.

member with pathological grade (Table I), clinical stage (Table II), TP53 mutation status (Table III) and chemotherapy 
Table IV. Associations between elevated SIRT mRNA expression and overall survival of all patients with ovarian cancer, according to different chemotherapy methods.

\begin{tabular}{|c|c|c|c|c|}
\hline SIRT & Chemotherapy method & Cases, $\mathrm{n}$ & HR (95\% CI) & P-value \\
\hline \multirow[t]{3}{*}{ SIRT1 } & Contains Platinum & 1,049 & $1.21(1.05-1.40)$ & 0.0092 \\
\hline & Contains Taxol & 793 & $1.25(1.03-1.51)$ & 0.0207 \\
\hline & Contains Taxol+Platinum & 776 & $1.28(1.06-1.55)$ & 0.0113 \\
\hline \multirow[t]{3}{*}{ SIRT2 } & Contains Platinum & 1,049 & $0.90(0.76-1.05)$ & 0.1792 \\
\hline & Contains Taxol & 793 & $0.88(0.73-1.07)$ & 0.1980 \\
\hline & Contains Taxol+Platinum & 776 & $0.88(0.73-1.07)$ & 0.2007 \\
\hline \multirow[t]{3}{*}{ SIRT3 } & Contains Platinum & 1,049 & $0.83(0.70-0.97)$ & 0.0199 \\
\hline & Contains Taxol & 793 & $0.77(0.64-0.93)$ & 0.0069 \\
\hline & Contains Taxol+Platinum & 776 & $0.81(0.67-0.98)$ & 0.0289 \\
\hline \multirow[t]{3}{*}{ SIRT4 } & Contains Platinum & 1,049 & $1.26(1.09-1.44)$ & 0.0014 \\
\hline & Contains Taxol & 793 & $1.31(1.07-1.60)$ & 0.0090 \\
\hline & Contains Taxol+Platinum & 776 & $1.30(1.06-1.60)$ & 0.0111 \\
\hline \multirow[t]{3}{*}{ SIRT5 } & Contains Platinum & 478 & $0.79(0.62-1.00)$ & 0.0540 \\
\hline & Contains Taxol & 357 & $0.82(0.61-1.10)$ & 0.1903 \\
\hline & Contains Taxol+Platinum & 356 & $0.82(0.61-1.11)$ & 0.2017 \\
\hline \multirow[t]{3}{*}{ SIRT6 } & Contains Platinum & 1,049 & $0.81(0.70-0.93)$ & 0.0031 \\
\hline & Contains Taxol & 793 & $0.77(0.63-0.94)$ & 0.0094 \\
\hline & Contains Taxol+Platinum & 776 & $0.75(0.61-0.92)$ & 0.0057 \\
\hline \multirow[t]{3}{*}{ SIRT7 } & Contains Platinum & 1,049 & $0.79(0.68-0.90)$ & 0.0008 \\
\hline & Contains Taxol & 793 & $0.74(0.61-0.89)$ & 0.0014 \\
\hline & Contains Taxol+Platinum & 776 & $0.74(0.60-0.91)$ & 0.0043 \\
\hline
\end{tabular}

The number of patients expressing SIRT5 is different compared with all the other SIRT genes. The expression level of SIRT5 is affected by factors such as study design, patient selection and statistical analyses. Platinum, platinum-based therapies; SIRT, sirtuin; HR, hazard ratio.

choice (Table IV) were determined. Table II shows that SIRT1 and SIRT4 were significantly associated with poor OS in patients with stage III/IV OC, whereas SIRT3 and SIRT5 predicted improved OS. Moreover, SIRT6 and SIRT7 were associated with favorable OS in patients with stage I/II OC, as well as those with stage III/IV. Consistent to the KM outcomes, SIRT2 exhibited no association with OS in patients with stage I/II or III/IV. With regard to the pathological grade in Table I, SIRT2 and SIRT4 indicated poor OS in pathological grades I and III, respectively. However, SIRT3 and SIRT7 were associated with significantly improved OS in patients with OC of pathological grades II and III, respectively. Elevated levels of SIRT6 exhibited a significant association with improved OS in both pathological grades II and III. In terms of TP53 mutation (Table III), the results demonstrated the significant associations of SIRT2 and SIRT5 with OS in patients with OC that have a TP53 mutation. In addition, SIRT3 was associated with favorable OS in patients with mutant and wild-type TP53. With the exception of SIRT2 and SIRT5, the associations between high mRNA expression levels of other SIRT family members and chemotherapy agents were significant (Table IV).

Tumor xenograft and IHC results. Fig. S1 represents excised tumors with scale bars and tumor volume over time statistical graph (Fig. S1B and S1C). In addition, using IHC staining it was demonstrated that SIRT1, SIRT3, SIRT6 were expressed in various degrees in the tumor tissues (Fig. S1A).

\section{Discussion}

$\mathrm{OC}$ is one of the most lethal types of gynecological malignancies, which affects the health condition of female patients worldwide. Despite the development of medical technology, the incidence and OS rates remain unsatisfactory, due to the unique biological characteristics of OC (24). Thus, identifying a novel biomarker for the prognostic prediction of $\mathrm{OC}$ is necessary. Previously, the SIRT family has been reported to serve a critical part in the process of tumorigenesis (25-27). Each individual SIRT may act either as a tumor suppressor or an oncogene in different types of malignancies, potentially via tumor-associated signaling pathways or mitosis regulation $(13,28,29)$. However, the specific association between SIRTs and OC remains controversial, and remains to be further clarified.

In the present study, the prognostic values of seven individual SIRTs were comprehensively assessed in OC via the KM plotter online database. According to the analysis, most of the SIRT members act as either tumor promoters or inhibitors in OC. As a consequence, the high mRNA expression levels of SIRT1 and SIRT4 were associated with an unfavorable prognosis in patients with OC. Similarly, previous studies have also verified the roles of the aforementioned two SIRTs in other carcinomas, such as lung cancer $(30,31)$, breast cancer $(32-34)$, gastric cancer $(35,36)$, and prostate cancer (37). Specifically, Shin et al (30) reported that high SIRT1 expression was identified in non-small cell 
lung cancer, which was highly associated with drug resistance via the SIRT1-mitogen-activated protein kinase signaling pathway. Additionally, SIRT1 could aggravate invasion capacity and metastasis in prostate cancer via the induction of epithelial-to-mesenchymal transition (37). Consistently, the present study demonstrated that elevated mRNA levels of SIRT1 were associated with poor OS in patients with OC, notably those at a high clinical stage (III+IV) and those that received chemotherapy. SIRT4 has been demonstrated to be a tumor suppressor as it causes inhibition of cell proliferation and metastasis (38). To the best of our knowledge, no study has reported the prognostic value of SIRT4 in OC. The present study demonstrated that SIRT4 expression was inversely associated with prognosis in OC. In patients with OC of a high clinical stage (III+IV), poor differentiation (pathological grade III) and who received chemotherapy, high SIRT4 expression was associated with unfavorable OS. This observation may provide a novel insight into the effect of SIRT4 on the regulation of OC. Above all, these results support the use of SIRT1 and SIRT4 as potential biomarkers for prognostic prediction in OC.

The tumor suppressive effects of SIRT3, SIRT5, SIRT6 and SIRT7 in OC were also determined in the present study. To the best of our knowledge, mitochondrial localized SIRT3 (39), with its unique characteristic, serves as a crucial regulator of the Warburg effect (40) in breast cancer via the inhibition of reactive oxygen species and the destabilization of HIF-1 $\alpha$. Previous studies have demonstrated that SIRT3 can suppress the metastasis capacity and induce apoptosis in OC $(18,41)$. Consistently, the KM plotter results of the present study demonstrated that high SIRT3 expression may be associated with a favorable prognosis in patients. Additionally, patients with pathological grade II, a high clinical stage (III+IV), a TP53 mutation and those who received chemotherapy experienced improved OS, further indicating that increased SIRT3 expression predicts prolonged OS. SIRT5 has been reported to possess dual roles in the regulation of various types of carcinoma, suggesting that SIRT5 acts as a tumor suppressor in hepatic cancer by inhibiting acyl-CoA oxidase 1 (42). However, SIRT5 has also been demonstrated to function as an oncogene in the carcinogenesis of colorectal cancer (CRC), potentially by stimulating glutamine metabolism through the activation of dehydrogenase 1 during the tricarboxylic-acid cycle in CRC cells (43). The fact that SIRT5 exhibits dual effects on the regression of different tumors may depend on the dominant factor in the microenvironment and the signaling pathway. In the present study, SIRT5 overexpression was associated with a favorable prognosis in OC, and elevated SIRT5 levels in patients with clinical stage III+IV and TP53 mutations were associated with improved OS, implying that SIRT5 is a potential biomarker of OC. Previous studies referring to SIRT6 have investigated its role as a tumor suppressor, and its decreased expression is associated with poor OS in patients with pancreatic cancer (44), hepatic carcinoma (45) and colon cancer (46). The present study demonstrated that SIRT6 overexpression was associated with good prognosis in OC. An increased SIRT6 level also predicted favorable OS in patients with poor differentiation (pathological grades II+III), in all clinical stages and in patients who received chemotherapy. However, Bae et al (19) have demonstrated that SIRT6 expression is notably associated with a poor prognosis in OC. This difference could be attributed to the patient selection, sample size, study design, statistical method and detection means (the present study focused on mRNA expression, whereas the former study focused on the protein degrees). According to the SIRT7 mRNA analysis, the present study revealed that increased levels of SIRT7 predicted a good prognosis in patients with OC, notably those with serous cancer and pathological grade II and in all clinical stages. Additionally, SIRT7 overexpression was associated with improved OS in patients who received any type of chemotherapy. The data in the present study differed from those described in previous studies, in that SIRT7 acted as an oncogene in tumor progression $(14,47,48)$, which provides a novel basis for predicting the potential of SIRT7 in OC.

Furthermore, the analysis using the KM plotter of each of the SIRT members revealed contradictory associations with PFS, PPS and OS. Theoretically, OS may better represent patient prognosis (in contrast to PFS and PPS); however, because PFS and PPS compose OS, OS is in turn affected by these two factors (49). These conflicting associations may partially result from differences in the chemotherapy choice, sample size, sensitivity to diagnosis and treatment between two SIRT expression groups $(50,51)$. Therefore, the PFS and PPS data may provide another direction for further studies investigating the role of the SIRT family in the prognosis of OC.

In conclusion, the present study suggested that the mRNA expression levels of SIRTs (SIRT1, SIRT3, SIRT4, SIRT5, SIRT6 and SIRT7) are associated with prognosis in patients with OC. Additionally, it was revealed that the SIRT family members demonstrated potential prediction capability for other clinicopathological features, including the histological type, pathological grade, clinical stage, TP53 mutation status and mainstream chemotherapy choice. However, these results are limited to the mRNA expression levels of SIRTs. Therefore, analysis of the protein expression levels is required in future studies. Overall, the present study provides a novel prospect for future studies on specific signaling pathways through which SIRTs may participate in the tumorigenesis, progression and metastasis of OC.

\section{Acknowledgements}

The authors would like to thank Dr Jie Zhang (Department of Hepatobiliary Surgery, The First Affiliated Hospital of Wenzhou Medical University) for their technical help.

\section{Funding}

The present study was supported by the Natural Science Foundation of China (grant no. 81470874).

\section{Availability of data and materials}

The datasets used and/or analyzed during the current study are available from the corresponding author on reasonable request.

\section{Authors' contributions}

LW and QH conceived and designed the present study. KC and PG analyzed the data. QH, RY and ND wrote the manuscript. 
RY performed the animal experiments and histological examinations. ND revised the manuscript for intellectual content and analyzed the data. All authors read and approved the final manuscript.

\section{Ethics approval and consent to participate}

The animal study was approved by the Wenzhou Medical University Ethics Committee (approval no. wydw2019-0214).

\section{Patient consent for publication}

Not applicable.

\section{Competing interests}

The authors declare that they have no competing interests.

\section{References}

1. Siegel RL, Miller KD and Jemal A: Cancer statistics, 2016. CA Cancer J Clin 66: 7-30, 2016.

2. Siegel RL, Miller KD and Jemal A: Cancer statistics, 2019. CA Cancer J Clin 69: 7-34, 2019.

3. Chen X, Xu Z, Zeng S, Wang X, Liu W, Qian L, Wei J, Yang X, Shen Q, Gong Z and Yan Y: SIRT5 downregulation is associated with poor prognosis in glioblastoma. Cancer Biomark 24: 449-459, 2019.

4. Jayson GC, Kohn EC, Kitchener HC and Ledermann JA: Ovarian cancer. Lancet 384: 1376-1388, 2014.

5. Coleman MP, Forman D, Bryant H, Butler J, Rachet B, Maringe C, Nur U, Tracey E, Coory M, Hatcher J, et al: Cancer survival in Australia, Canada, Denmark, Norway, Sweden, and the UK, 1995-2007 (the International Cancer Benchmarking Partnership): An analysis of population-based cancer registry data. Lancet 377: 127-138, 2011.

6. Kane AE and Sinclair DA: Sirtuins and $\mathrm{NAD}^{+}$in the development and treatment of metabolic and cardiovascular diseases. Circ Res 123: 868-885, 2018.

7. Singh CK, Chhabra G, Ndiaye MA, Garcia-Peterson LM, Mack NJ and Ahmad N: The role of sirtuins in antioxidant and redox signaling. Antioxid Redox Signal 28: 643-661, 2018.

8. O'Callaghan C and Vassilopoulos A: Sirtuins at the crossroads of stemness, aging, and cancer. Aging Cell 16: 1208-1218, 2017.

9. Karbasforooshan H, Roohbakhsh A and Karimi G: SIRT1 and microRNAs: The role in breast, lung and prostate cancers. Exp Cell Res 367: 1-6, 2018

10. Hu Y, Lin J, Lin Y, Chen X, Zhu G and Huang G: Overexpression of SIRT4 inhibits the proliferation of gastric cancer cells through cell cycle arrest. Oncol Lett 17: 2171-2176, 2019.

11. Park EY, Woo Y, Kim SJ, Kim DH, Lee EK, De U, Kim KS, Lee J, Jung JH, Ha KT, et al: Anticancer effects of a new SIRT inhibitor, MHY2256, against human breast cancer MCF-7 cells via regulation of MDM2-p53 binding. Int J Biol Sci 12: $1555-1567,2016$

12. Huang G, Cui F, Yu F, Lu H, Zhang M, Tang H and Peng Z: Sirtuin-4 (SIRT4) is downregulated and associated with some clinicopathological features in gastric adenocarcinoma. Biomed Pharmacother 72: 135-139, 2015.

13. Kim HS, Vassilopoulos A, Wang RH, Lahusen T, Xiao Z, Xu X, Li C, Veenstra TD, Li B, Yu H, et al: SIRT2 maintains genome integrity and suppresses tumorigenesis through regulating APC/C activity. Cancer Cell 20: 487-499, 2011.

14. Yu H, Ye W, Wu J, Meng X, Liu RY, Ying X, Zhou Y, Wang H, Pan C and Huang W: Overexpression of sirt7 exhibits oncogenic property and serves as a prognostic factor in colorectal cancer. Clin Cancer Res 20: 3434-3445, 2014.

15. Azuma Y, Yokobori T, Mogi A, Altan B, Yajima T, Kosaka T, Onozato R, Yamaki E, Asao T, Nishiyama M and Kuwano H: SIRT6 expression is associated with poor prognosis and chemosensitivity in patients with non-small cell lung cancer. J Surg Oncol 112: 231-237, 2015.
16. Shuang T, Wang M, Zhou Y and Shi C: Over-expression of Sirt1 contributes to chemoresistance and indicates poor prognosis in serous epithelial ovarian cancer (EOC). Med Oncol 32: 260, 2015.

17. Pinton G, Nilsson S and Moro L: Targeting estrogen receptor beta $(E R \beta)$ for treatment of ovarian cancer: Importance of KDM6B and SIRT1 for ER $\beta$ expression and functionality. Oncogenesis 7 : $15,2018$.

18. Wu Y, Gao WN, Xue YN, Zhang LC, Zhang JJ, Lu SY, Yan XY Yu HM, Su J and Sun LK: SIRT3 aggravates metformin-induced energy stress and apoptosis in ovarian cancer cells. Exp Cell Res 367: 137-149, 2018.

19. Bae JS, Noh SJ, Kim KM, Park SH, Hussein UK, Park HS, Park BH, Ha SH, Lee H, Chung MJ, et al: SIRT6 is involved in the progression of ovarian carcinomas via $\beta$-catenin-mediated epithelial to mesenchymal transition. Front Oncol 8: 538, 2018.

20. Zhang J, Yin XJ, Xu CJ, Ning YX, Chen M, Zhang H, Chen SF and Yao LQ: The histone deacetylase SIRT6 inhibits ovarian cancer cell proliferation via down-regulation of Notch 3 expression. Eur Rev Med Pharmacol Sci 19: 818-824, 2015.

21. Györffy B, Lanczky A, Eklund AC, Denkert C, Budczies J, Li Q and Szallasi Z: An online survival analysis tool to rapidly assess the effect of 22,277 genes on breast cancer prognosis using microarray data of 1,809 patients. Breast Cancer Res Treat 123: 725-731, 2010.

22. Györffy B, Surowiak P, Budczies J and Lánczky A: Online survival analysis software to assess the prognostic value of biomarkers using transcriptomic data in non-small-cell lung cancer. PLoS One 8: e82241, 2013.

23. Gyorffy B, Lánczky A and Szállási Z: Implementing an online tool for genome-wide validation of survival-associated biomarkers in ovarian-cancer using microarray data from 1287 patients. Endocr Relat Cancer 19: 197-208, 2012.

24. Qin L, Qiu H, Zhang M, Zhang F, Yang H, Yang L, Jia L, Qin K, Jia L, Dou X, et al: Soluble CD40 ligands sensitize the epithelial ovarian cancer cells to cisplatin treatment. Biomed Pharmacother 79: 166-175, 2016.

25. Giannopoulou AF, Velentzas AD, Konstantakou EG, Avgeris M, Katarachia SA, Papandreou NC, Kalavros NI, Mpakou VE, Iconomidou V, Anastasiadou E, et al: Revisiting histone deacetylases in human tumorigenesis: The paradigm of urothelial bladder cancer. Int J Mol Sci 20, 2019.

26. Huang G and Zhu G: Sirtuin-4 (SIRT4), a therapeutic target with oncogenic and tumor-suppressive activity in cancer. Onco Targets Ther 11: 3395-3400, 2018.

27. Geng $\mathrm{CH}$, Zhang CL, Zhang JY, Gao P, He M and Li YL: Overexpression of Sirt6 is a novel biomarker of malignant human colon carcinoma. J Cell Biochem 119: 3957-3967, 2018.

28. Serrano L, Martínez-Redondo P, Marazuela-Duque A, Vazquez BN, Dooley SJ, Voigt P, Beck DB, Kane-Goldsmith N, Tong Q, Rabanal RM, et al: The tumor suppressor SirT2 regulates cell cycle progression and genome stability by modulating the mitotic deposition of H4K20 methylation. Genes Dev 27: 639-653, 2013.

29. Lee BB, Kim Y, Kim D, Cho EY, Han J, Kim HK, Shim YM and Kim DH: Metformin and tenovin-6 synergistically induces apoptosis through LKB1-independent SIRT1 down-regulation in non-small cell lung cancer cells. J Cell Mol Med 23: 2872-2889, 2019.

30. Shin DH, Choi YJ and Park JW: SIRT1 and AMPK mediate hypoxia-induced resistance of non-small cell lung cancers to cisplatin and doxorubicin. Cancer Res 74: 298-308, 2014.

31. Fu L, Dong Q, He J, Wang X, Xing J, Wang E, Qiu X and Li Q: SIRT4 inhibits malignancy progression of NSCLCs, through mitochondrial dynamics mediated by the ERK-Drp1 pathway. Oncogene 36: 2724-2736, 2017.

32. Lee H, Kim KR, Noh SJ, Park HS, Kwon KS, Park BH, Jung SH, Youn HJ, Lee BK, Chung MJ, et al: Expression of DBC1 and SIRT1 is associated with poor prognosis for breast carcinoma. Human Pathol 42: 204-213, 2011

33. Jin X, Wei Y, Xu F, Zhao M, Dai K, Shen R, Yang S and Zhang N: SIRT1 promotes formation of breast cancer through modulating Akt activity. J Cancer 9: 2012-2023, 2018.

34. Jeong SM, Xiao C, Finley LW, Lahusen T, Souza AL, Pierce K, Li YH, Wang X, Laurent G, German NJ, et al: SIRT4 has tumor-suppressive activity and regulates the cellular metabolic response to DNA damage by inhibiting mitochondrial glutamine metabolism. Cancer Cell 23: 450-463, 2013.

35. Cha EJ, Noh SJ, Kwon KS, Kim CY, Park BH, Park HS, Lee H, Chung MJ, Kang MJ, Lee DG, et al: Expression of DBC1 and SIRT1 is associated with poor prognosis of gastric carcinoma. Clin Cancer Res 15: 4453-4459,2009. 
36. Sun H, Huang D, Liu G, Jian F, Zhu J and Zhang L: SIRT4 acts as a tumor suppressor in gastric cancer by inhibiting cell proliferation, migration, and invasion. Onco Targets Ther 11: 3959-3968, 2018.

37. Byles V, Zhu L, Lovaas JD, Chmilewski LK, Wang J, Faller DV and Dai Y: SIRT1 induces EMT by cooperating with EMT transcription factors and enhances prostate cancer cell migration and metastasis. Oncogene 31: 4619-4629, 2012.

38. Csibi A, Fendt SM, Li C, Poulogiannis G, Choo AY, Chapski DJ, Jeong SM, Dempsey JM, Parkhitko A, Morrison T, et al: The mTORC1 pathway stimulates glutamine metabolism and cell proliferation by repressing SIRT4. Cell 153: 840-854, 2013.

39. Pryds K, Nielsen RR, Jorsal A, Hansen MS, Ringgaard S, Refsgaard J, Kim WY, Petersen AK, Bøtker HE and Schmidt MR: Effect of long-term remote ischemic conditioning in patients with chronic ischemic heart failure. Basic Res Cardiol 112: 67, 2017.

40. Warburg O: On the origin of cancer cells. Science 123: 309-314, 1956.

41. Dong XC, Jing LM, Wang WX and Gao YX: Down-regulation of SIRT3 promotes ovarian carcinoma metastasis. Biochem Biophys Res Commun 475: 245-250, 2016.

42. Chen XF, Tian MX, Sun RQ, Zhang ML, Zhou LS, Jin L, Chen LL, Zhou WJ, Duan KL, Chen YJ, et al: SIRT5 inhibits peroxisomal ACOX1 to prevent oxidative damage and is downregulated in liver cancer. EMBO Rep 19: 2018.

43. Wang YQ, Wang HL, Xu J, Tan J, Fu LN, Wang JL, Zou TH, Sun DF, Gao QY, Chen YX and Fang JY: Sirtuin5 contributes to colorectal carcinogenesis by enhancing glutaminolysis in a deglutarylation-dependent manner. Nat Commun 9: 545, 2018

44. Kugel S, Sebastián C, Fitamant J, Ross KN, Saha SK, Jain E, Gladden A, Arora KS, Kato Y, Rivera MN, et al: SIRT6 suppresses pancreatic cancer through control of Lin28b. Cell 165: 1401-1415, 2016.

45. Marquardt JU, Fischer K, Baus K, Kashyap A, Ma S, Krupp M, Linke M, Teufel A, Zechner U, Strand D, et al: Sirtuin-6-dependent genetic and epigenetic alterations are associated with poor clinical outcome in hepatocellular carcinoma patients. Hepatology 58: 1054-1064, 2013.
46. Li N, Mao D, Cao Y, Li H, Ren F and Li K: Downregulation of SIRT6 by miR-34c-5p is associated with poor prognosis and promotes colon cancer proliferation through inhibiting apoptosis via the JAK2/STAT3 signaling pathway. Int J Oncol, 2018.

47. Wei W, Jing ZX, Ke Z and Yi P: Sirtuin 7 plays an oncogenic role in human osteosarcoma via downregulating CDC4 expression. Am J Cancer Res 7: 1788-1803, 2017.

48. Li H, Tian Z, Qu Y, Yang Q, Guan H, Shi B, Ji M and Hou P. SIRT7 promotes thyroid tumorigenesis through phosphorylation and activation of $\mathrm{Akt}$ and $\mathrm{p} 70 \mathrm{~S} 6 \mathrm{~K} 1$ via DBC1/SIRT1 axis. Oncogene 38: 345-359, 2019.

49. He WZ and Xia LP: RE: Detecting overall survival benefit derived from survival postprogression rather than progression-free survival. J Natl Cancer Inst: Oct 16, 2015 (Epub ahead of print). doi: 10.1093/jnci/djv311.

50. Sundar S, Wu J, Hillaby K, Yap J and Lilford R: A systematic review evaluating the relationship between progression free survival and post progression survival in advanced ovarian cancer. Gynecol Oncol 125: 493-499, 2012.

51. Shimokawa M, Ohki M and Kaku T: Correlation of progression-free and post-progression survival with overall survival in phase III trials of first-line chemotherapy for advanced epithelial ovarian cancer. Eur J Gynaecol Oncol 36: 370-375, 2015.

52. Telloni SM: Tumor staging and grading: A primer. Methods Mol Biol 1606: 1-17, 2017.

53. Šišovská I, Minář L, Felsinger M, Anton M, Bednaříková M, Hausnerová J, Jandáková E and Weinberger V: Current FIGO staging classification for cancer of ovary, fallopian tube and peritoneum. Ceska Gynekol 82: 230-236, 2017 (In Czech).

This work is licensed under a Creative Commons Attribution-NonCommercial-NoDerivatives 4.0 International (CC BY-NC-ND 4.0) License. 